\title{
Violência obstétrica: conceituações sobre sua implicação no parto
}

\author{
Obstetric violence: concepts about its implication in childbirth \\ Violencia obstétrica: conceptos sobre su implicación en la entrega
}

Recebido: 25/09/2021 | Revisado: 30/09/2021 | Aceito: 04/10/2021 | Publicado: 05/10/2021

\author{
Natalia Barbosa Sousa \\ ORCID: https://orcid.org/0000-0002-8739-4887 \\ Faculdade Integrada Carajás, Brasil \\ E-mail: nathaliabarbosa555@gmail.com \\ Karyna Oliveira Matos \\ ORCID: https://orcid.org/0000-0002-9789-1959 \\ Faculdade Integrada Carajás, Brasil \\ E-mail: karynaoliver18@gmail.com \\ Patricia Maria Lima Silva de Sousa \\ ORCID: https://orcid.org/0000-0002-2985-5163 \\ Faculdade Integrada Carajás, Brasil \\ E-mail: patriciasousa50anos@gmail.com
}

\begin{abstract}
Resumo
O processo de parto sempre foi encarado como um dos momentos mais especiais da vida de uma mulher. Entretanto, as situações de violência obstétrica durante o período gravídico puerperal são muito presentes em instituições públicas e privadas, ocasionando um acontecimento doloroso tanto de forma física ou psicológica. Sendo assim, este artigo teve como objetivo descrever a violência obstétrica e suas implicações no bem-estar da parturiente e investigar a produção cientifica atual acerca do tema, e demostrar métodos que possibilitem a qualidade da assistência. $\mathrm{O}$ estudo constitui-se de uma revisão integrativa da literatura, com abordagem teórica. Foram selecionados inicialmente 43 artigos que abordavam os descritores, que após análise do objeto de estudo e os critérios de inclusão, restaram 21 artigos, no idioma: português, publicados entre os anos de 2014 e 2020. Os critérios de exclusão foram publicações de tese, dissertação, monografia e materiais duplicados e artigos não relacionados diretamente à temática da pesquisa. A mulher tem direito de escolha da assistência obstétrica, deve, portanto, ter a sua dignidade assegurada no que concerne aos princípios básicos dos direitos sexuais e reprodutivos. Consideram-se necessárias mudanças nas práticas assistenciais obstétricas vigentes, visando a reduzir as intervenções desnecessárias, é promover ações de humanização do cuidado.
\end{abstract}

Palavras-chave: Violência obstétrica; Humanização da assistência; Violência contra a mulher; Parto.

\begin{abstract}
The birth process has always been seen as one of the most special moments in a woman's life. However, situations of obstetric violence during the pregnancy and puerperal period are very present in public and private institutions, causing a painful event both physically and psychologically. Thus, this article aimed to describe obstetric violence and its implications for the well-being of parturients and to investigate the current scientific production on the subject, and demonstrate methods that enable the quality of care. The study consists of an integrative literature review with a theoretical approach. 43 articles were initially selected that addressed the descriptors, which after analyzing the object of study and the inclusion criteria, remained 21 articles, in the language: Portuguese, published between 2014 and 2020. The exclusion criteria were thesis publications, dissertation, monograph and duplicate materials and articles not directly related to the research theme. Women have the right to choose obstetric care, therefore, they must have their dignity assured with regard to the basic principles of sexual and reproductive rights. Changes in current obstetric care practices are considered necessary, in order to reduce unnecessary interventions, and to promote actions of humanization of care.
\end{abstract}

Keywords: Obstetric violence; Humanization of care; Violence against women; Childbirth.

\section{Resumen}

El proceso del parto siempre se há considerado uno de los momentos más especiales en la vida de una mujer. Sin embargo, las situaciones de violencia obstétrica durante el embarazo y el puerperio están muy presentes en las instituciones públicas y privadas, provocando un evento doloroso tanto física como psicológicamente. Así, este artículo tuvo como objetivo describir la violencia obstétrica y sus implicaciones para el bienestar de las parturientas e investigar la producción científica actual sobre el tema, y demostrar métodos que posibiliten la calidad de la atención. El estudio consiste en una revisión integradora de la literatura con un enfoque teórico. Se seleccionaron inicialmente 43 artículos que abordaron los descriptores, que luego de analizar el objeto de estudio y los criterios de inclusión, quedaron 21 artículos, en el idioma: portugués, publicados entre 2014 y 2020. Los criterios de exclusión fueron 
publicaciones de tesis, disertación, monografía y duplicado. materiales y artículos no relacionados directamente con el tema de investigación. Las mujeres tienen derecho a elegir la atención obstétrica, por lo tanto, deben tener asegurada su dignidad con respecto a los principios básicos de los derechos sexuales y reproductivos. Los cambios en las prácticas actuales de atención obstétrica se consideran necesarios para reducir las intervenciones innecesarias y promover acciones de humanización de la atención.

Palabras clave: Violencia obstétrica; Humanización del cuidado; Violencia contra la mujer; Parto.

\section{Introdução}

A violência obstétrica é definida como qualquer ação que produza efeitos negativos, físico ou psicológico durante o período entre o pré-natal, o parto e o pós-parto, que inclui perda da autonomia e decisão sobre seus corpos, principalmente por se tratar de um momento de grande vulnerabilidade para a mulher.

O parto sempre foi encarado como um momento significativo na vida das mulheres. Entretanto, as situações de violência durante o período gravídico puerperal são muito presentes em instituições públicas e privadas, ocasionando um acontecimento doloroso e traumático, somado e múltiplas intervenções e direitos violados (Rodrigues, et al., 2017).

Nota-se que, com o passar do tempo, a cesárea passou a ser tratada como um produto de consumo e não como uma intervenção para melhoria dos resultados nos partos. No Brasil ainda não existe uma legislação específica de violência obstétrica, que regulamente ou puna os crimes praticados contra as mulheres por profissionais de saúde e os responsabilize.

Mediante a um ato tão preocupante vimos a necessidade de nos inteirar mais sobre o assunto, descobrindo ainda mais, outros tipos de negligências e atos violentos que a mulher também por sua vez desconhece, tais como: isolamento, jejum forçado, restringir a gestante ao leito para a mesma não se movimentar, raspagem de pelos pubianos de forma inadequada, ter braços e pernas amarradas, utilizar fármacos sem autorização, agressões físicas e humilhações dentre outras e principalmente intervir o contato físico da mãe e filho logo após o nascimento.

Em oposição a esta violência, o movimento pela humanização do parto tem crescido, tendo objetivo centrado na mulher que tem autonomia é a protagonista, não ocorrendo intervenções desnecessárias e, no caso de intervenções necessárias, há diálogo com o obstetra sobre as medidas que serão tomadas.

Espera-se que, por meio da produção desse conhecimento a assistência obstétrica seja construída livre de atos violentos e pautada pelo respeito aos direitos sexuais, reprodutivos e humanos, garantindo um atendimento mais respeitoso, com autonomia da mulher e participação da família (Jardim \& Modena, 2018).

Com um papel fundamental os profissionais de saúde, devem buscar em sua assistência o vínculo com a parturiente para proporcionar um parto saudável, e assegurar o acesso ao atendimento digno, evitando assim a violência obstétrica.

Este estudo se justifica pela temática abordada como assunto de suma importância na conscientização individual e coletiva dos profissionais de saúde principalmente por quem sofre violência obstétrica, assunto esse que vem se tornando uma prática bastante comum dentro das instituições de saúde.

Portanto, o objetivo desse artigo é descrever a violência obstétrica e suas implicações no bem-estar da parturiente e investigar a produção cientifica atual acerca do tema, buscando demostrar métodos que possibilitem a qualidade da assistência.

\section{Definições e Termos acerca da Violência Obstétrica}

O conceito de violência obstétrica são atos desrespeitosos, tais como, assédio moral e físico, negligência e abuso acometidos contra gestantes, parturientes e puérperas (Rodrigues, et al., 2017). As consequências para as mulheres que sofreram violência obstétrica são diversas e abrangem tanto a dimensão biopsicossocial, como vergonha, medo angustia e traumas em gestações futuras, como a dimensão física, que envolve inflamações e dores persistentes devido a intervenções médicas desnecessárias (Carneiro, 2015). 
De acordo com Ministério da Saúde (2014) a gravidez e o nascimento são uma das experiências humanas mais importantes na vida da mulher e isso vale para todos os envolvidos. Este é um processo singular uma experiência especial na vida da mulher. No entanto, esse acontecimento vem sendo alvo de atos agressivos tanto de forma psicológica quanto física, e a falta de desrespeito ao direito de decisão por parte das parturientes.

Anteriormente, a assistência ao parto ficava sob a responsabilidade das parteiras, cuja atuação se baseava no conhecimento empírico. Nesse contexto, o parto era realizado em ambiente domiciliar e seu processo fisiológico é respeitado, ao longo dos anos o processo de parturição sofreu mudanças significativas (Nascimento, et al., 2019).

No Brasil, o termo "violência obstétrica" é usado para descrever várias formas de violência que ocorrem durante a gravidez, parto, pós-parto e aborto. Outros descritores usados no mesmo fenômeno também foram encontrados, como violência no parto, violência de gênero no parto e aborto, abuso obstétrico, assistência desumana, violação dos direitos humanos da mulher durante o parto entre outros (Diniz, et al., 2015).

Conforme a Organização Mundial de Saúde foi reconhecido, em 2014, o termo violência obstétrica como problema de saúde pública que afeta diretamente o direto das mulheres e seus bebês. Uma em cada quatro mulheres brasileiras sofre violência no parto segundo pesquisa realizada, em 2010, pela Fundação Perseu Abramo: "Mulheres brasileiras e Gênero nos espaços público e privado".

No Brasil, a atenção à mulher na gestação e parto permanece como um desafio para a assistência, tanto no que se refere à qualidade propriamente dita, quanto aos princípios filosóficos do cuidado, ainda centrado em um modelo medicalizante.

A violência obstétrica é considerada como uma invasão do corpo feminino pelos profissionais de saúde, que ocorre no momento da gravidez, parto, pós-parto, inclusive no atendimento ao aborto. Segundo Pereira et al. (2016), são situações recorrentes envolvendo práticas e condutas de negligência, e maus tratos vivenciadas por grávidas durante o trabalho de parto, muitas vezes prejudicial e não baseada em evidências científicas.

Dessa forma, a mulher pode se tornar um objeto de manipulações sem consentimento ou sem a informação suficiente sobre os processos a serem realizados.

De acordo com a pesquisa da Fundação Perseu Abramo, realizada em 2010, 25\% das mulheres brasileiras sofrem violência no parto. Esse modelo de assistência tem como resultado a permanência de elevadas taxas de mortalidade materna e de morbidade perinatal, além de colocar o Brasil como país com as maiores taxas de cesárea no mundo.

Essas práticas submetem as mulheres a regras rígidas e muitas vezes desnecessárias que não respeitam seus corpos e ritmos naturais e as impedem de exercer suas funções.

\section{Práticas de Violência Obstétrica e suas Implicações no Bem-Estar das Mulheres}

Na pesquisa "Nascer no Brasil" foi um estudo nacional de base hospitalar, realizado com 23.940 puérperas e seus recém-nascidos, que evidência excesso de intervenções desnecessárias durante o parto e muitas vezes prejudiciais, podendo causar iatrogênias (Leal, et al., 2014). Esta violência que muitas vezes é vivenciada pelas mulheres de forma silenciosa, por medo ou por opressão, produz angustia num momento em que deveria estar ocorrendo acolhimento e cuidado.

Em relação às intervenções realizadas durante o parto, a pesquisa revelou que a posição de litotomia (deitada com a face para cima e joelhos flexionados) foi utilizada em $92 \%$ dos casos, a manobra de Kristeller (aplicação de pressão na parte superior do útero) teve uma ocorrência de 37\% e a episiotomia (corte na região do períneo) ocorreu em 56\% dos partos. Essas ações intervencionistas e muitas vezes, desnecessárias, têm ocasionado a insatisfação das mulheres, que são relegadas a coadjuvantes nos processos de parto e nascimento. 
São inúmeras as formas de violência obstétrica que ocorrem em todos os hospitais, na rede pública e privada. Essa situação pode levá-las a se conformarem com a exploração de seus corpos por diferentes pessoas, aceitando diversas situações incômodas sem reclamar.

De acordo com Souza e Castro (2014), o aumento da morbidade materna e infantil está relacionado ao alto índice de cesarianas, com internação em UTI, uso excessivo de ocitocina e episiotomia causando hemorragias e infecção em gestantes, e aumentando o tempo de permanência no hospital. Percebe-se que a alta taxa de cesáreas indica o grau de hipermedicalização nas maternidades.

Constatou-se a manifestação de procedimentos obstétricos desnecessárias como, por exemplo, episiotomia, manobra de Kristeller, uso da tricotomia, proibição de ingerir alimentos ou bebidas, cesariana sem justificativa e o risco dessa cirurgia, tratar a mulher em trabalho de parto de maneira rude ou sem empatia, e a posição horizontal no parto, que além de retardar o trabalho de parto, aumenta as dores da contração e tantas outras formas que não podem ser ignoradas (Martins, et al., 2019).

Além disso, as mulheres são proibidas quanto a presença do acompanhante, de sua escolha em algum momento durante a sua internação, tendo em vista que a Organização Mundial de Saúde (2014), recomenda que a parturiente tenha um acompanhante, devido os benefícios no que diz respeito o suporte emocional contínuo e sensação de segurança.

Desta forma, a parturiente perde a sua autonomia no momento do parto, além de implicar em danos emocionais psicológicos, tornando a mulher insatisfeita diante do parto e a desistir de futuras gestações.

No que diz respeito à episiotomia, o Ministério da Saúde (2014), afirma que a sua realização rotineira deve ser abandonada da prática obstétrica, somente em situações onde os benefícios possam ser maiores que os riscos, como por exemplo, distócia de ombro, parto pélvico, fórceps ou extrações a vácuo, ou em casos que a sua não realização pode resultar em maiores lacerações e trauma perineal.

Portanto, percebe-se que as características do modelo de atenção obstétrico brasileiro, incluindo a falta de preparo institucional hospitalar, e reconhecido como extremamente intervencionista e tanto pela necessidade de um parto rápido onde o respeito a autonomia da mulher em algumas situações é esquecido, favorecendo a ocorrência de intervenções desnecessárias (Carvalho \& Brito, 2017).

Os hospitais brasileiros precisam se adequar aos direitos humanos das mulheres em seu ciclo gravídico puerperal, deixando estas estruturas tradicionais e ultrapassadas para trás e promovendo ambientes mais favoráveis à atuação holística dos profissionais, garantindo uma assistência mais digna à mulher e seu recém-nascido. Uma boa alternativa para esta melhoria é a construção de centros de partos normais, pois seus históricos de atuação têm os melhores resultados perinatais para partos normais, fisiológicos e de risco eventual.

\section{Cuidados de Enfermagem para a Prevenção da Violência Obstétrica}

De acordo com Moura et al. (2018) o papel do enfermeiro na assistência durante período gravídico-puerperal, é realizar boas práticas obstétricas, no intuito de prevenir a ocorrência da violência obstétrica deve reconhecer a individualidade de cada mulher para tornar a humanização do parto mais efetiva.

Além disso, o enfermeiro torna-se o profissional da saúde mais próximo da mulher no momento do parto. O enfermeiro é respaldado pela Lei do exercício profissional n. 7.498 de 25 de junho de 1986 para atuar diretamente no cuidado à mulher em trabalho de parto.

Para a realização plena de um processo de parto humanizado e necessária a formação de profissionais da saúde conscientes do problema e dispostos a intervir sempre a favor da paciente. Isso possibilita o acolhimento, a escuta da gestante e o protagonismo da mulher no parto (Souza, et al., 2016). 
Outra medida preventiva é assegurar a redução de procedimentos invasivos, como incisões perineais, rupturas de membranas, a indução do trabalho de parto, em casos de cesarianas justifica o motivo (Castro \& Rocha, 2020). Nesse contexto, importante orientar e encorajar as mulheres no uso de métodos não farmacológicos como banhos de imersão e spray, massagens parte inferior das costas, o uso de bolas de parto, que ajudar no alívio da dor e evita intervenções inapropriadas.

O enfermeiro deve trabalhar valorizando e respeitando as emoções da parturiente, deve garantir o acesso a uma assistência digna e um atendimento humanizado em todas as fases da gestação, e assim sendo protagonista do próprio parto (Castro \& Rocha, 2020).

O papel do enfermeiro obstetra na assistência ao parto de baixo risco ou de risco habitual pode ser uma medida capaz de reduzir intervenções desnecessárias durante o trabalho de parto, oferecendo um cuidado mais integral à mulher e sua família, sendo momentos informativos às gestantes. O cuidado obstétrico baseado em evidências é aquele que oferece assistência, apoio e proteção, com o mínimo de intervenções necessárias.

Portanto, os autores Silva et al. (2014) apontam que a enfermagem obstétrica é capaz de exercer uma transformação em posturas e comportamentos violentas da assistência obstétrica, afirmando a Organização Mundial da Saúde e do Ministério da Saúde, por meio de seu programa atual de humanização da Rede Cegonha que a categoria profissional mais adequada para a transformação do histórico brasileiro e do fortalecimento de uma assistência segura ao processo de parto e nascimento.

A humanização no parto é adotada como política oficial no Brasil no ano 2000, com o Programa de Humanização no Pré-natal e Nascimento (PHPN), com o objetivo de abranger centenas de instituições e garantir a equidade de todas as gestantes.

Em 2001, reformulando um novo programa o Ministério da Saúde editou o manual Parto, Aborto e Puerpério Assistência Humanizada a mulher, que defende a necessidade de garantir a privacidade e a prestação do cuidado que efetivamente promovam benefícios à mulher.

Acreditamos que esta humanização deva começar na primeira consulta de pré-natal, pois uma gestante que tenha recebido um bom preparo nesta fase seja, por orientações adequadas, chegam mais preparadas aos hospitais tanto emocionalmente e fisicamente, por ter melhor o conhecimento de seus direitos legais.

Como estratégia para lidar com essa realidade brasileira, o Ministério da Saúde, desenvolveu o Programa Maternidade Segura que objetiva respeitar a dignidade humana, os sentimentos, as escolhas e preferências de todas as mulheres, portanto, é mais do que a prevenção de mortes e morbidades e sim o desenvolvimento de um olhar holístico sobre as mulheres.

Vale ressaltar que para entender a contribuição do cuidado humanizado é necessário que os profissionais de saúde, utilizem prática clínica baseada em evidências cientifica e no atendimento pré-natal para desempenhar um papel importante no atendimento à mulher, cuidado baseado no apoio emocional e respeito (Silva, et al., 2020).

Para que a parturiente seja bem assistida neste momento peculiar de sua vida, cabe aos profissionais da saúde a criação e utilização de conhecimentos científicos sistematizados e direcionados para a necessidade individual com um cuidado holístico e respeitoso

\section{Metodologia}

O estudo constitui-se de uma revisão integrativa da literatura, definida por Souza et al. (2010) como um instrumento que utiliza a síntese de conhecimentos e aplicação de resultados de estudos de um determinado assunto, além de apontar lacunas que precisam ser preenchidas por novos estudos. A referida pesquisa traz como informações referentes as formas de violências obstétricas e suas implicações no parto, além de contribuir para a identificação de medidas preventivas para um parto humanizado. A busca dos artigos foi realizada em três bases de dados eletrônicos, acessados na Biblioteca Virtual em 
Saúde (BVS): Literatura Latino-Americana e do Caribe em Ciências da Saúde (Lilacs), Scientific Electronic Library Online (SciELO).

Para o levantamento dos estudos foram utilizados os descritores: "violência obstétrica", "violência no parto e pósparto", "impacto da violência obstétrica", "parto humanizado", no idioma português adaptados de acordo com a base de dados utilizada.

A busca foi realizada no mês de agosto de 2021, foram selecionados inicialmente 43 artigos que abordavam os descritores, que após análise do objeto de estudo e os critérios de inclusão, restaram 21 artigos, conforme Figura 1.

Figura 1 - Fluxograma do processo de busca e seleção dos estudos inclusos na revisão. Redenção/PA, Brasil, 2021.

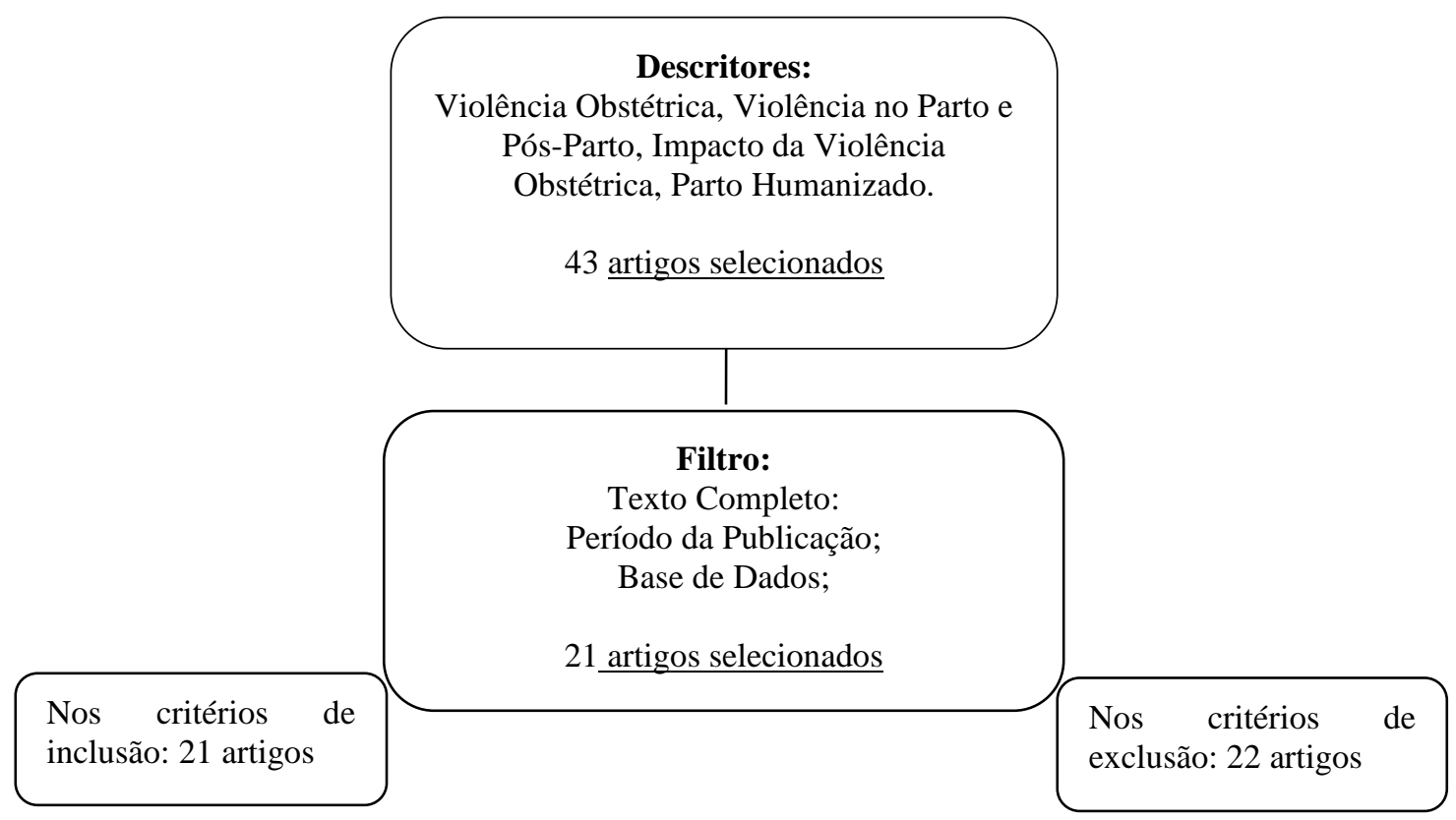

Fonte: Autores (2021).

Para selecionar a amostra, foram utilizados os seguintes critérios de inclusão: ser artigo original, indexado nas bases de dados selecionadas, no idioma: português, publicados entre os anos de 2014 e 2020. Os critérios de exclusão foram publicações de tese, dissertação, monografia e materiais duplicados e artigos não relacionados diretamente à temática da pesquisa. 


\section{Resultados e Discussão}

Tabela 1.

\begin{tabular}{|c|c|c|c|}
\hline Autor/ano & Título & Objetivo & Resultados \\
\hline $\begin{array}{l}\text { Brasil, } \\
(2014)\end{array}$ & $\begin{array}{l}\text { Humanização do Parto e do } \\
\text { Nascimento. }\end{array}$ & $\begin{array}{l}\text { Analisar a garantia ao } \\
\text { acesso com qualidade } \\
\text { do parto, e práticas } \\
\text { democráticas na gestão. }\end{array}$ & $\begin{array}{l}\text { Os estudos permitiram observar um } \\
\text { conjunto de lutas pelo direito à saúde e ao } \\
\text { acesso de qualidade equânime as mulheres } \\
\text { grávidas. }\end{array}$ \\
\hline $\begin{array}{l}\text { OMS, } \\
(2014)\end{array}$ & $\begin{array}{l}\text { Prevenção e eliminação de } \\
\text { abusos, desrespeito e maus- } \\
\text { tratos durante o parto em } \\
\text { instituições de saúde. }\end{array}$ & $\begin{array}{l}\text { Discutir o direito a um } \\
\text { cuidado de saúde digno } \\
\text { e respeitoso. }\end{array}$ & $\begin{array}{l}\text { Ações com participação de mulheres, } \\
\text { comunidades, profissionais e gestores da } \\
\text { saúde para apoiar e garantir que todas as } \\
\text { mulheres tenham acesso à assistência } \\
\text { respeitosa, competente e atenciosa. }\end{array}$ \\
\hline $\begin{array}{l}\text { Leal et al., } \\
\text { (2014) }\end{array}$ & $\begin{array}{l}\text { Intervenções obstétricas } \\
\text { durante o trabalho e parto em } \\
\text { mulheres brasileiras de risco } \\
\text { habitual. }\end{array}$ & $\begin{array}{l}\text { Descrever as boas } \\
\text { práticas de atenção ao } \\
\text { parto e as intervenções } \\
\text { obstétricas, realizadas } \\
\text { em mulheres de risco } \\
\text { obstétrico habitual. }\end{array}$ & $\begin{array}{l}\text { As pesquisas evidenciaram que menos de } \\
\text { um terço desse grupo de mulheres com } \\
\text { risco obstétrico habitual se alimentou } \\
\text { durante o trabalho de parto e utilizou } \\
\text { procedimentos não farmacológicos para } \\
\text { alívio da dor. }\end{array}$ \\
\hline $\begin{array}{l}\text { Silva et al., } \\
\text { (2014) }\end{array}$ & $\begin{array}{l}\text { Violência obstétrica na visão } \\
\text { de enfermeiras obstetras. }\end{array}$ & $\begin{array}{l}\text { Relatar a experiência de } \\
\text { enfermeiras obstetras } \\
\text { sobre a violência } \\
\text { obstétrica vivenciada. }\end{array}$ & $\begin{array}{l}\text { Os estudos permitiram observar, a } \\
\text { necessidade de mudanças com os } \\
\text { profissionais no modelo da assistência } \\
\text { obstétrica, na grade curricular durante a } \\
\text { formação dos profissionais técnicos em } \\
\text { obstetrícia. }\end{array}$ \\
\hline $\begin{array}{l}\text { Souza \& } \\
\text { Castro, } \\
(2014)\end{array}$ & $\begin{array}{l}\text { Sobre o parto e o nascer: a } \\
\text { importância da prevenção } \\
\text { quaternária. }\end{array}$ & $\begin{array}{lr}\text { Identificar } & \text { as } \\
\text { ocorrências } & \text { de } \\
\text { complicações } & \text { maternas } \\
\text { e neonatais } & \end{array}$ & $\begin{array}{l}\text { Estudos demostram que as mulheres devem } \\
\text { reconquista seu protagonismo durante o } \\
\text { parto, fortalecendo também o sistema de } \\
\text { saúde para que seja capaz de promover um } \\
\text { serviço humanizado. }\end{array}$ \\
\hline $\begin{array}{l}\text { Carneiro, } \\
(2015)\end{array}$ & $\begin{array}{l}\text { Para chegar ao Bojador, é } \\
\text { preciso ir além da dor: } \\
\text { sofrimento no parto e suas } \\
\text { potencialidades. }\end{array}$ & $\begin{array}{lr}\text { Analisar } & \text { sobre } \\
\text { concepções de dor e de } \\
\text { sofrimento } \\
\text { atualidade. }\end{array}$ & $\begin{array}{l}\text { As pesquisas evidenciaram que a dor e } \\
\text { sofrimento podem ser ambíguos os seus } \\
\text { territórios, e como podem acessar canais da } \\
\text { existência antes pouco pensados, como } \\
\text { tornar a dor a bandeira de uma causa social. }\end{array}$ \\
\hline $\begin{array}{l}\text { Diniz et al., } \\
\text { (2015) }\end{array}$ & $\begin{array}{l}\text { Violência Obstétrica como } \\
\text { questão para a Saúde Pública } \\
\text { no Brasil: origens, definições, } \\
\text { tipologia, impactos sobre a } \\
\text { saúde materna, e propostas } \\
\text { para sua prevenção. }\end{array}$ & $\begin{array}{l}\text { Introduzir um debate de } \\
\text { forma a auxiliá-lo na } \\
\text { busca sobre aspectos } \\
\text { específicos que podem } \\
\text { ser aborda- dos como } \\
\text { temas de pesquisa e } \\
\text { intervenção. }\end{array}$ & $\begin{array}{l}\text { As pesquisas evidenciaram que as } \\
\text { intervenções em saúde pública têm sido } \\
\text { utilizadas como propostas para prevenir e } \\
\text { mitigar a violência obstétrica. }\end{array}$ \\
\hline $\begin{array}{l}\text { Souza et al., } \\
\text { (2016) }\end{array}$ & 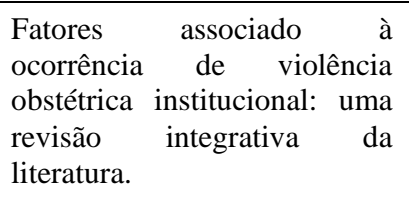 & $\begin{array}{l}\text { Analisar os fatores que } \\
\text { envolve as ocorrências } \\
\text { de violência obstétrica. }\end{array}$ & $\begin{array}{l}\text { A partir da identificação dos fatores é } \\
\text { possível intervir de forma que possibilitar o } \\
\text { incentivo aos gestores para implementar as } \\
\text { práticas de ensino humanizado e melhorias } \\
\text { na qualidade de serviços de saúde pública. }\end{array}$ \\
\hline $\begin{array}{l}\text { Pereira et al., } \\
\text { (2016) }\end{array}$ & $\begin{array}{l}\text { Violência Obstétrica: ofensa à } \\
\text { dignidade humana. }\end{array}$ & $\begin{array}{l}\text { Esclarecer as variadas } \\
\text { formas de violência } \\
\text { obstétrica, abordando os } \\
\text { princípios bioéticas que } \\
\text { são negligenciados. }\end{array}$ & $\begin{array}{l}\text { A fim de evitar uma maior incidência da } \\
\text { VO o Ministério da Saúde criou políticas } \\
\text { que visam garantir os direitos das gestantes } \\
\text { e fazer com o que o parto seja humanizado } \\
\text { e respeitoso. }\end{array}$ \\
\hline $\begin{array}{l}\text { Carvalho \& } \\
\text { Brito, } \\
\text { (2017) }\end{array}$ & $\begin{array}{llr}\text { Formas } & \text { de } & \text { violência } \\
\text { obstétrica } & \text { vivenciadas por } \\
\text { puérperas } & \text { que tiveram parto } \\
\text { normal. } & & \end{array}$ & $\begin{array}{lr}\text { Demonstrar as } & \text { formas } \\
\text { de violência } & \text { obstétrica } \\
\text { vivenciadas } & \text { por } \\
\text { puérperas. } & \end{array}$ & $\begin{array}{l}\text { Os relatos das puérperas retratam as formas } \\
\text { de violência obstétrica da qual foram } \\
\text { vítimas, caracterizadas por palavras e } \\
\text { atitudes dos profissionais de saúde que as } \\
\text { assistiram. }\end{array}$ \\
\hline
\end{tabular}




\begin{tabular}{|c|c|c|c|}
\hline $\begin{array}{l}\text { Rodrigues } \\
\text { et al., } \\
\text { (2017) }\end{array}$ & $\begin{array}{l}\text { Violência obstétrica } \\
\text { processo de parturição em } \\
\text { maternidades vinculadas à } \\
\text { Rede Cegonha }\end{array}$ & $\begin{array}{lr}\text { Identificar a violência } \\
\text { institucional } & \text { contra } \\
\text { mulheres no processo } \\
\text { de parturição } & \text { em } \\
\text { maternidades } & \\
\text { vinculadas a } & \text { Rede } \\
\text { Cegonha. } & \end{array}$ & $\begin{array}{l}\text { A pesquisa demostra a importância de um } \\
\text { atendimento humanizado adequado através } \\
\text { da estruturação e organização da atenção } \\
\text { materno-infantil proposto pela rede } \\
\text { cegonha. }\end{array}$ \\
\hline
\end{tabular}

Fonte: Autores (2021).

Diante da pesquisa realizada por Moura et al. (2018) com objetivo na literatura científica nacional, a assistência de enfermagem na prevenção da violência obstétrica, os profissionais devem buscar em sua assistência o vínculo com a parturiente para proporcionar um parto saudável, evitando assim a violência.

Na visão de Jardim e Modena (2018) os resultados demostram que a violência obstétrica retrata uma violação dos direitos humanos e um grave problema de saúde pública, revelada nos atos discriminatórios e desrespeitosos praticados por profissionais de saúde.

A partir da análise de Martins et al. (2019) teve como resultados conscientizar as mulheres a respeito da violência obstétrica ajudando-as a identificar atos que possam ser considerados violentos.

Para Nascimento et al. (2019) as pesquisas evidenciaram necessidade de implementação de medidas que assegurem assistência humanizada e estratégias de empoderamento das mulheres de modo que passem a ser protagonistas no ato de parturição.

Em 2010 a Fundação Perseu Abramo, realizou uma pesquisa nacional de opinião pública, de mulheres brasileiras e gênero nos espaços público e privado. Com o movimento de humanização do atendimento ao parto e a formulação de novas estratégias para contribuir na qualidade de vida das mulheres.

O enfermeiro é respaldado pela lei do exercício profissional n. 7.498 de 25 de junho de 1986 para atuar diretamente no cuidado à mulher em trabalho de parto. Destacando-se na redução de procedimentos invasivos, através de métodos não farmacológicos, o acolhimento digno e apoio físico e emocional.

Diante disso, temos por resultado a grande evidencia de que, o cuidado de enfermagem contribuir na redução de procedimentos invasivos, através de métodos não farmacológicos, o acolhimento digno, escuta ativa e apoio físico e emocional.

\section{Considerações Finais}

A partir da pesquisa, é possível compreender que o parto é o nascimento e um momento inesquecível na vida da mulher, e qualquer comportamento que interfira nesse ciclo é intolerável, que as mulheres são as protagonistas desse momento e os profissionais de saúde são apenas os facilitadores desse processo com uma assistência digna e humanizada. No contexto do parto, a necessidade de promover um entorno de saúde mais adequado, o qual os procedimentos sejam mais regularizados, e assim propiciem um ambiente mais seguro.

A violência obstétrica se expressa de forma naturalizada, muitas vezes de forma invisível. Tais como procedimentos desnecessários, manobra de Kristeller, o uso excessivo de medicamentos e a proibição de acompanhante, que são realizados sem o consentimento da mulher e que não seja baseado em evidências científicas atuais sejam de caráter físico e psicológico. Além disso, a presença de acompanhante que é garantido por lei proporciona conforto a parturiente, bem como pode diminuir os casos de violência obstétrica. Os profissionais de saúde têm um papel fundamental nas modificações das condutas posturais e violentas na assistência obstétrica. 
Com o presente estudo espera-se fomentar a produção cientifica, a fim de produzir mais conhecimentos acerca da temática, bem como mudanças nas práticas assistenciais vigentes, visando a reduzir as intervenções desnecessárias e as violações aos diretos das mulheres.

\section{Referências}

Brasil. (2014). Ministério da Saúde. Humanização do parto e do nascimento. Caderno humaniza SUS. 4, 465.

Brasil, (1986). Conselho Federal de Enfermagem, Lei do exercício profissional n. 7.498 de 25 de junho de 1986. Dispõe sobre a regulamentação do exercício da enfermagem e dá outras providências.

Brasil. (2011). Ministério da Saúde. Secretaria de atenção à saúde. Manual prático para implementação da rede cegonha. 1, 1-42.

Carneiro, R. (2015). “Para chegar ao Bojador, é preciso ir além da dor”: sofrimento no parto e suas potencialidades. Sexualidad, Salud y Sociedad. $20,91-112$.

Castro, A. T. \& Rocha, S. P. (2020). Violência obstétrica e os cuidados de enfermagem: reflexões a partir da literatura. Revisão Integrativa de Literatura. 11, $176-81$.

Carvalho, I. S. \& Brito, R. S. (2017). Formas de violência obstétrica vivenciadas por puérperas que tiveram parto normal. Revista Eletrônica Trimestral De Enfermeira. 16, 80-8

Diniz, S. G., Salgado, H. D. O., Andrezzo, H. F. D. A., Carvalho, P. G. C D., Carvalho, P. C. A., Aguiar, C. A. D., \& Niy, D. Y. (2015). Violência obstétrica como questão para a saúde pública no Brasil: origens, definições, tipologia, impactos sobre a saúde materna, e propostas para sua prevenção. Revista Brasileira e desenvolvimento humano. Jornal of Human Growth and Development. 25, 377-384.

Jardim, D. M. B. \& Modena, C. M. A. (2018). Violência obstétrica no cotidiano assistencial e suas características. Revista Latino-Americana de Enfermagem. 26,3069

Rodrigues, F. A. C., Lira, P. H. M., Freitas, A. L. V., Mitros, V. M. S., \& Almeida, P. C. (2017). Violência obstétrica no processo de parturição em maternidades vinculadas à rede cegonha. Revista Sociedade Brasileira de Reprodução Humana. 32, 78-84.

Leal, M. C., Pereira, A. P. E., Domingues, R. M. S. M., Theme, M. M. F., Dias, M. A. B., Nakamura, P. M., Bastos, M. H., \& Gama, G. N. (2014). Intervenções obstétricas durante o trabalho de parto e parto em mulheres brasileiras de risco habitual. Caderno Saúde Pública. $30,17-47$.

Martins, F. L., Silva, B. O., Carvalho, F. L. O., Costa, D. M., Paris, L. R. P., Guidi, L. R. J., Bueno, D. M. P., \& David, M. L. (2019). Violência obstétrica: uma expressão nova para um problema histórico. Revista Saúde em Foco. 11, 413.

Moura, R. C. M., Pereira, T. F., Rebouças, F. J., Costa. C. M., Lernades, A. M. G., Silva, L. K. A., \& Rocha, K. M. M. (2018). Cuidados de enfermagem na prevenção da violência obstétrica. Revista Enfermagem Foco. 9, 60-65.

Nascimento, S. L., Pires, V. M. M., Santos, N. A., Machado, J. C., Meira, L. S., \& Palmarella, V. P. R. (2019). Conhecimentos e experiências de violência obstétrica em mulheres que vivenciaram a experiência do parto. Revista Enfermeira Actual. 37, 1-14.

Organização Mundial Da Saúde. (2014). Prevenção e eliminação de abusos, desrespeito e maus-tratos durante o parto em instituições de saúde. Genebra: Departamento de Saúde Reprodutiva e Pesquisa/OMS

Pereira, J. S., Silva, J. C O., Borges, N. A., Ribeiro, M. M., Auarek, L. J., \& Souza, J. H. K. (2016). Violência obstétrica: ofensa à dignidade humana. Brazilian Journal of Surgery and Clinical Research. 15, 103-108.

Silva, T. M., Sousa, K. H. J. F., Oliveira, A. D. S., Amorim, F. C. M., \& Almeida, C. A. P. L (2020). Violência obstétrica: a abordagem da temática na formação de enfermeiros obstétricos. Acta Paul Enferm. 33, 1-8.

Silva, M. G. Da., Marcelino, M. C., Rodrigues, L. S. P., \& Torro, R. C. (2014). Violência obstétrica na visão de enfermeiras obstetras. Revista da Rede de Enfermagem do Nordeste, 15, 720-728.

Souza, M. T. D., Silva, M. D. D., \& Carvalho, R. D. (2010). Revisão integrativa: o que é e como fazer. Einstein (São Paulo), 8(1), $102-106$.

Souza, A. B., Silva, L. C., Alves, R. N., \& Alarcão, A. C. J. (2016). Fatores associados à ocorrência de violência obstétrica institucional: revisão integrativa da literatura. Revista Ciência Médica. 25, 115-128.

Souza, J. P. \& Castro, C. P. (2014). Sobre o parto e o nascer: a importância da prevenção quaternária. Caderno Saúde Pública. $30,11-13$.

Venturi, W., Bokany, V., Dias, G., Alba, D., Rosas, W., \& Figueiredo, N. (2010). Mulheres Brasileiras e Gênero nos Espaços Públicos e Privado. Fundação Perseu Abramo e SESC. (São Paulo). 